\title{
ANALISIS KESESUAIAN PENGGUNAAN LAHAN PADA DAERAH RAWAN TANAH LONGSOR DI KABUPATEN TEGAL
}

\author{
Anggun Prima Gilang Rupaka ${ }^{1}$, Suharyanto ${ }^{2}$, Sudarno $^{3}$ \\ ${ }^{1}$ Program Magister IImu Lingkungan Universitas Diponegoro, Semarang \\ ${ }^{2}$ Jurusan Teknik Sipil Fakultas Teknik Universitas Diponegoro, Semarang \\ ${ }^{3} J u r u s a n$ Teknik Lingkungan Fakultas Teknik Lingkungan Universitas Diponegoro, Semarang
}

\begin{abstract}
The frequency of landslides in Tegal regency increasing every year. The distribution area are also more widespread, especially in districts Jatinegara, Bojong and Bumijawa. These regions has a hilly topography profile with a height ranging from 400 - 1200 meters above sea level. The landslide's factors that use as the parameters in this study are rainfall, slope, soil type, depth of soil solum and land use. Suitability of land use based on the level of vulnerability to landslides associated with the level of capacity and vulnerability, because the area that not conform based on these factors are the residential area.

The method used to calculate and analyze the landslide-prone area in this study are with the help of GIS. The software were used to analyze consist of ArcGIS 10, ER Mapper 7.0 and Basemap. Satellite images digitized with ArcGIS to produce maps of land use. Then the land-use maps overlaid with maps of slope, soil type maps, rainfall maps and depth of solum. Predefined values for each parameter were then summed and classified based on assessment standards. The landslide susceptibility map is then used to analyze the suitability of land in landslide-prone areas in Tegal regency. The level of capacity and vulnerability to disasters in areas prone to landslides obtained by interview in the form of a questionnaire.

Subdistrict Jatinegara, Bojong and Bumijawa has an area of 25.000 hectares, $37,81 \%$ of the area that included in the "Landslide Prone" category, while the $59.82 \%$ of the area goes into the "Pretty-Prone Landslide" category. Conversion of forest land into agricultural production into is the one of the factors that aggravate the landslide that happened. Villagers who live in landslide-prone areas do not have the awareness that cutting down trees and intensive agriculture are causing landslides that in their area, in addition to soil type and slope factors that dominant. Vulnerability and capacity to landslides in the region included in the low category. Factors that influence are economic level, education level, living conditions and the condition of the access road.
\end{abstract}

Key words: Landslide, GIS, Land Suitability, Tegal.

\section{PENDAHULUAN}

Bencana longsor merupakan salah satu bencana alam yang sering terjadi di Indonesia. Potensi longsor di Indonesia sejak tahun 1998 hingga pertengahan 2008 , tercatat 647 kejadian bencana, dimana $85 \%$ dari bencana tersebut merupakan bencana banjir dan longsor (Fadli, 2009). Indonesia yang berada di daerah tropis memiliki curah hujan yang berkisar $>2000$ $\mathrm{mm} / \mathrm{tahun}$. Selain faktor curah hujan, wilayah Indonesia yang berbukit-bukit, penebangan hutan liar, alih fungsi hutan dengan sudut kelerengan yang besar menjadi lahan pertanian yang menyebabkan longsor sering terjadi.

Tanah longsor merupakan perpindahan massa tanah secara alami yang terjadi dalam waktu singkat dan volume yang besar (Arsyad, 2000). Fenomena alam ini berubah menjadi bencana alam tanah longsor manakala tanah longsor tersebut menimbulkan korban baik berupa korban jiwa maupun kerugian harta benda dan hasil budaya manusia. Ketersediaan informasi yang lengkap dan akurat mengenai pengendalian pemanfaatan lahan di kawasan rawan tanah longsor beserta peraturan yang bisa dijadikan dasar dalam setiap aktivitas pengembangan merupakan hal yang sangat diperlukan demi mencegah dan meminimalkan korban jiwa dan dampak ekonomi yang ditimbulkan oleh bencana alam tanah longsor, dan lebih jauh sebagai masukan bagi penyusunan tata ruang dalam suatu kawasan rawan tanah longsor. Kabupaten Tegal menurut posisi geografis terletak di $108^{\circ} 57^{\prime} 6^{\prime \prime}-109^{\circ} 21^{\prime}$ $30^{\prime \prime}$ BT dan $6^{\circ} 50^{\prime} 41^{\prime \prime}-7^{\circ} 15^{\prime} 30^{\prime \prime}$ LS. Secara administratif wilayah Kabupaten Tegal terbagi menjadi 18 kecamatan yang meliputi 281 Desa dan 6 kelurahan. Luas wilayah Kabupaten Tegal mencapai $87.879 \mathrm{Ha}$. Dari seluruh kecamatan 
yang ada, tujuh diantaranya memiliki wilayah yang memiliki topografi berbukit-bukit, yaitu Jatinegara, Margasari, Balapulang, Bojong, sebagian Pangkah dan Kedungbanteng. Wilayah pegunungan dan perbukitan memiliki resiko bahaya longsor yang besar.

\section{TUJUAN}

1. Mencari tingkat kesesuaian penggunaan lahan bila dibandingkan dengan tingkat kerawanan longsor di Kecamatan Jatinegara, Bojong dan Bumijawa.

2. Menggali informasi tentang kondisi fisik alam, sosial dan penyebab pemanfaatan lahan pada wilayah rawan longsor serta membuat peta kerawanan bencana longsor di Kabupaten Tegal.

3. Memberikan rekomendasi pada masyarakat yang tinggal di daerah rawan longsor dan mengetahui peran serta pemerintah daerah dalam memberikan arahan pada masyarakat tentang bahaya longsor.

\section{METODOLOGI}

Lokasi penelitian dapat dilihat pada Gambar $1 \mathrm{di}$ bawah ini:

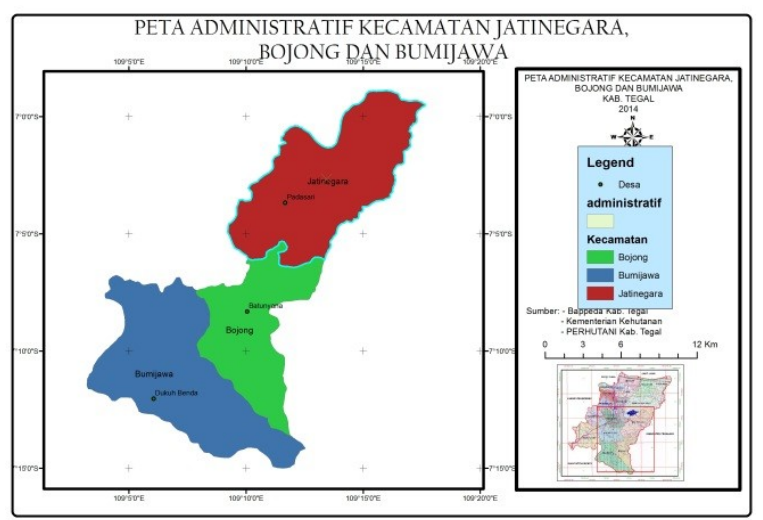

Gambar 1. Lokasi Penelitian

Klasifikasi longsor di wilayah Kabupaten Tegal akan menggabungkan dua versi klasifikasi parameter longsor dari Kementerian Kehutanan dan Kementerian Pertanian. Hal ini disebabkan oleh kondisi bentang alam Kabupaten Tegal khususnya di Kecamatan Jatinegara, Bojong dan Bumijawa yang spesifik terhadap masing-masing klasifikasi longsor dari kedua Kementerian tersebut. Setelah dilakukan survey lapangan awal, dapat diambil kesimpulan bahwa klasifikasi yang akan digunakan adalah curah hujan, kelerengan lahan, penggunaan lahan, kedalaman solum tanah dan jenis batuan. Analisis kerawanan tanah longsor dengan menggunakan citra satelit Landsat, peta topografi atau DEM (Digital Elevation Model), Peta RTRW, Peta Jenis
Tanah dan Peta Penggunaan Lahan. Parameter longsor untuk Kabupaten Tegal dapat dilihat pada Tabel 1.

Tabel 1. Parameter Longsor Kabupaten Tegal

\begin{tabular}{|c|c|c|}
\hline No & Klasifikasi Longsor & Skor \\
\hline \multirow[t]{6}{*}{1.} & Kelerengan Lahan (\%) & \\
\hline & a. $<8$ & 1 \\
\hline & b. $8-15$ & 2 \\
\hline & c. $15-25$ & 3 \\
\hline & $25-45$ & 4 \\
\hline & e. $>45$ & 5 \\
\hline \multirow[t]{6}{*}{2.} & Kedalaman Solum (meter) & \\
\hline & a. $\quad$ Rendah $(<1)$ & 1 \\
\hline & b. Agak rendah $(1-2)$ & 2 \\
\hline & c. Sedang $(2-3)$ & 3 \\
\hline & d. Tinggi $(3-5)$ & 4 \\
\hline & e. Sangat tinggi $(>5)$ & 5 \\
\hline \multirow[t]{6}{*}{3.} & Penggunaan Lahan & \\
\hline & a. Hutan Alam & 1 \\
\hline & b. Hutan/Perkebunan & 2 \\
\hline & c. Semak/belukar/rumput & 3 \\
\hline & d. Tegalan/pekarangan & 4 \\
\hline & e. Sawah/pemukiman & 5 \\
\hline \multirow[t]{6}{*}{4.} & Curah Hujan & \\
\hline & a. Sangat Kering $(<1000)$ & 1 \\
\hline & b. Kering $(1001-2000)$ & 2 \\
\hline & c. Sedang $(2001-3000)$ & 3 \\
\hline & d. Basah $(3001-4000)$ & 4 \\
\hline & e. Sangat Basah $(\geq 4000)$ & 5 \\
\hline \multirow[t]{6}{*}{5.} & Jenis Batuan (Tanah) & \\
\hline & a. Dataran Aluvial & 1 \\
\hline & b. Perbukitan Kapur & 2 \\
\hline & c. Perbukitan Granit & 3 \\
\hline & d. Batuan sedimen & 4 \\
\hline & e. Bukit basal clay-shale & 5 \\
\hline
\end{tabular}

Sumber: BBSDLP Kementerian Pertanian dan Ditjen BPDASPS Kementerian Kehutanan.

Peta penggunaan lahan dibuat berdasarkan citra satelit dengan metode digitasi. Proses digitasi juga dilakukan untuk membuat peta jenis tanah, administrasi, kelerengan dan kedalaman solum tanah. Lalu skor dimasukkan ke dalam data pada ArcGIS maka dapat langsung di-overlay secara berjenjang untuk menentukan kerawanan longsor di wilayah Kecamatan Jatinegara, Bojong dan Bumijawa. Overlay berjenjang adalah suatu metode penilaian dengan cara meng-overlay-kan dua data terlebih dahulu kemudian gabungan kedua data tersebut di-overlay dengan data selanjutnya hingga data terakhir (Wuryanta, 2013). Sehingga didapatkan kriteria rawan longsor sebagai berikut: 
Tabel 2. Kriteria Penilaian Kerawanan Longsor

\begin{tabular}{|l|c|}
\hline $\begin{array}{c}\text { Kriteria Kerawanan } \\
\text { Longsor }\end{array}$ & Jumlah Skor \\
\hline Tidak Rawan & $<8$ \\
\hline Cukup Rawan & $8-14$ \\
\hline Rawan & $15-19$ \\
\hline Sangat Rawan & $20-25$ \\
\hline
\end{tabular}

\section{HASIL DAN PEMBAHASAN}

\section{Analisis Tingkat Kerawanan Longsor}

Hasil dari analisis parameter pemicu longsor dengan ArcGIS 10, didapat peta kerawanan longsor yang ditampilkan pada Gambar 2. Jika dilihat dari Gambar 2, terdapat tiga kategori yang dapat ditampilkan dari peta kerawanan longsor. Daerah yang berwarna kuning merupakan daerah dengan potensi longsor cukup tinggi dengan kategori "rawan", warna merah mewakili daerah yang "cukup rawan" dan warna hijau mewakili daerah yang "tidak rawan longsor". Data luas dari kriteria rawan longsor ditampilkan pada Tabel 3.

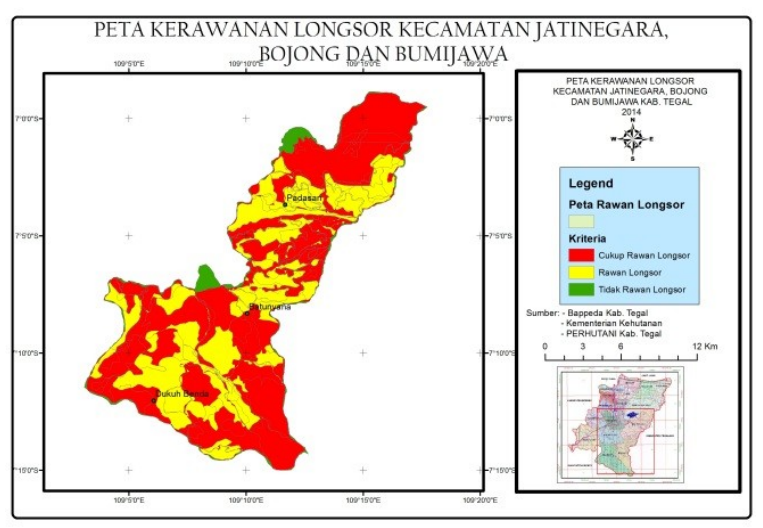

Gambar 2. Peta Kerawanan Longsor

Tabel 3. Luas Potensi Longsor Kabupaten Tegal (Ha).

\begin{tabular}{|l|c|c|c|}
\hline Kecamatan & $\begin{array}{c}\text { Tidak } \\
\text { Rawan } \\
\text { Longsor }\end{array}$ & $\begin{array}{c}\text { Cukup } \\
\text { Rawan } \\
\text { Longsor }\end{array}$ & $\begin{array}{c}\text { Rawan } \\
\text { Longsor }\end{array}$ \\
\hline Bojong & 105,9 & $4.139,2$ & $2.701,5$ \\
\hline Bumijawa & 109,3 & $4.848,5$ & $2.124,5$ \\
\hline Jatinegara & 393,9 & $6.415,8$ & $4.910,8$ \\
\hline $\begin{array}{l}\text { Total Luas } \\
\text { (Ha) }\end{array}$ & 609,1 & $15.403,5$ & $9.736,8$ \\
\hline $\begin{array}{l}\text { Persentase } \\
\text { (\%) }\end{array}$ & 2,37 & 59,82 & 37,81 \\
\hline
\end{tabular}

Jika dilihat dari Tabel 3, maka daerah dengan kriteria longsor paling rawan terdapat di kecamatan Jatinegara seluas 4.910,8 Ha. Hasil analisis spasial menunjukkan bahwa wilayah pemukiman seluas $686 \mathrm{Ha}$ masuk ke dalam wilayah yang memiliki kerawanan longsor yang tinggi. Faktor yang paling mempengaruhi adalah kelerengan, penggunaan lahan dan jenis tanah.

\section{Analisis Kesesuaian Penggunaan Lahan}

Kriteria-kriteria yang dimiliki suatu bentang lahan akan menentukan penggunaan lahan yang cocok pada daerah tertentu. Pengendalian penggunaan lahan menggunakan RTRW yang disusun oleh pemerintah daerah, khususnya Pemerintah Daerah Kabupaten Tegal. Berdasarkan UU No. 26 tahun 2007 dan Perda Kabupaten Tegal No. 10 tahun 2012, Faktor-faktor yang melatar belakangi disusunnya RTRW antara lain: kondisi fisik alam yang rentan rentan terhadap bencana; potensi sumberdaya alam, sumberdaya manusia dan sumberdaya buatan; kondisi ekonomi, sosial, budaya, politik, hukum, pertahanan keamanan, lingkungan hidup; ilmu pengetahuan dan teknologi; dan geostrategi, geopolitik dan geoekonomi.

Tabel 4. Luas Daerah Rawan Longsor Berdasarkan Penggunaan Lahan ( $\mathrm{Ha})$

\begin{tabular}{|l|r|r|r|r|}
\hline $\begin{array}{c}\text { Penggunaan } \\
\text { Lahan }\end{array}$ & $\begin{array}{c}\text { Cukup } \\
\text { Rawan } \\
\text { Longsor }\end{array}$ & $\begin{array}{c}\text { Rawan } \\
\text { Longsor }\end{array}$ & $\begin{array}{c}\text { Tidak } \\
\text { Rawan } \\
\text { Longsor }\end{array}$ & Total \\
\hline Belukar & 2780.2 & 1323.2 & 517.7 & 4621.1 \\
\hline Hutan & 3051.5 & 9.9 & 440.3 & 3501.7 \\
\hline Ladang & 1295 & 3181.1 & 146 & 4622.1 \\
\hline Pemukiman & 83.9 & 400.5 & 0 & 484.4 \\
\hline Perkebunan & 5225.8 & 984.4 & 125 & 6335.2 \\
\hline Sawah & 1775.3 & 4259.5 & 154.7 & 6189.5 \\
\hline Total & 14211.7 & 10158.6 & 1383.7 & 25754 \\
\hline
\end{tabular}

Alih fungsi penggunaan lahan di Kabupaten Tegal masih tergolong rendah. Namun bila dilihat dari sudut lain, yaitu alih fungsi lahan sebagai faktor penyebab longsor maka dapat dikatakan memiliki alih fungsi lahan yang tinggi. Perubahan fungsi kawasan hutan produksi menjadi lahan persawahan menjadi salah satu faktornya. Lahan persawahan memiliki skor yang tinggi dalam kriteria penentuan kawasan rawan longsor (Tabel 1). Pengawasan yang tidak ketat oleh Perhutani selaku pemilik lahan dan Bappeda selaku pemangku kepentingan menjadi faktor alhi fungsi lahan hutan menjadi persawahan, khususnya persawahan di daerah yang memiliki kelerengan yang tinggi dan beragam. 
Tabel 4 menunjukkan bahwa $82,68 \%$ dari luas wilayah pemukiman di Kecamatan Jatinegara, Bojong dan Bumijawa masuk dalam kategori Rawan Longsor. Data penduduk rawan terkena longsor dari BPBD menunjukkan bahwa $2,6 \%$ kepala keluarga dari Kecamatan Jatinegara, 7,98\% kepala keluarga dari Kecamatan Bojong dan 18,05\% kepala keluarga dari Kecamatan Bumijawa tinggal di daerah rawan longsor.

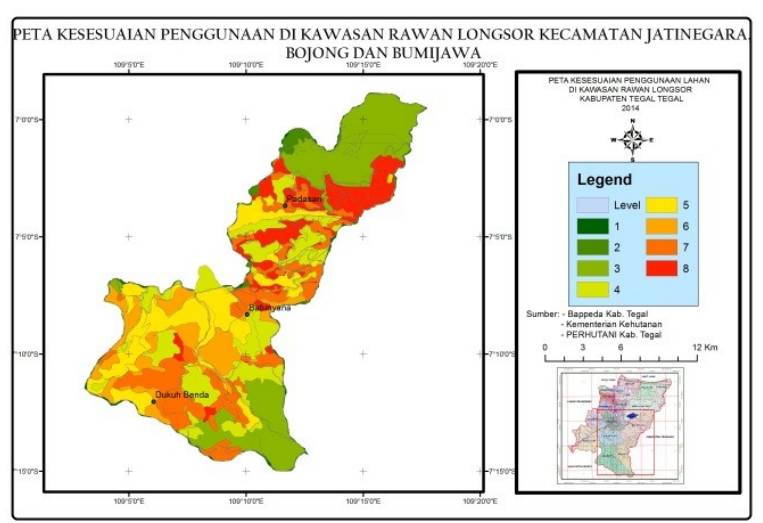

Gambar 3. Peta Kesesuaian Penggunaan Lahan pada Kawasan Rawan Longsor

Peta di atas hasil dari perhitungan skor penggunaan lahan dan skor kriteria rawan longsor yang telah dihitung sebelumnya. Level kesesuaian dibagi menjadi 8 sesuai dengan jumlah skor yang didapat dari penjumlahan skor penggunaan lahan dan kriteria rawan longsor. Angka 1 berarti "sangat sesuai" dan angka 8 berarti "sangat tidak sesuai". Jika peta tersebut di tumpang tindih dengan peta penggunaan lahan, maka wilayah pemukiman masuk kedalam level kesesuaian 8 yang artinya sangat tidak sesuai. Faktor yang menjadi parameter pada peta di atas adalah penggunaan lahan dan kerawanan longsor.

\section{KESIMPULAN DAN SARAN}

\section{Kesimpulan}

Kesesuaian antara penggunaan lahan di lapangan dengan RTRW Kabupaten Tegal telah mengalami penyimpangan. Penyimpangan seperti penambangan pasir liar dan alih fungsi lahan hutan menjadi lahan pertanian dapat diatasi dengan tindakan tegas dari pemerintah daerah selaku pemangku kepentingan. Kawasan yang tidak sesuai berdasarkan kerawanan longsor yang tinggi adalah pada kawasan pemukiman di wilayah kecamatan Jatinegara, Bojong dan Bumijawa.

Wilayah kabupaten Tegal yang diteliti meliputi kecamatan Jatinegara, Bojong dan
Bumijawa memiliki luas $29.310 \mathrm{Ha}, 37,81 \%$ dari luas wilayah yang termasuk dalam kategori "Rawan Longsor", sedangkan $59,82 \%$ dari luas wilayah lainnya merupakan wilayah dalam kategori "Cukup Rawan Longsor". Kawasan pemukiman menjadi salah satu kawasan yang masuk ke dalam kriteria Rawan Longsor.

Warga masyarakat yang tinggal di wilayah rawan longsor seperti desa Padasari kec. Jatinegara, desa Batu Nyana kec. Bojong dan desa Dukuh Benda kec. Bumijawa menyadari bahwa mereka tinggal di wilayah yang rawan longsor. Namun mereka tidak memiliki kesadaran untuk meminimalkan resiko bencana, tidak memiliki titik-titik evakuasi dan jauh dari rumah sakit atau puskesmas. Akses jalan yang rusak dan sering tertimbun longsoran tanah semakin menyulitkan mereka bila proses evakuasi berjalan.

\section{Saran}

1. Perangkat desa atau Karang Taruna di desa rawan longsor semestinya aktif dalam mengajak pihak pemerintah daerah atau swasta (NGO) untuk mengadakan penyuluhan bagi warga desa tentang bahaya dan mitigasi longsor.

2. Reboisasi dilaksanakan dengan menanam pohon yang memiliki nilai ekonomi yang rendah namun memiliki perakaran yang kuat untuk menahan tanah.

3. Melaksanakan program agroforestry pada kawasan hutan produksi yang beralih fungsi menjadi lahan pertanian agar tanaman yang memiliki perakaran dalam tetap terjaga keberadaannya.

4. Pembangunan talud di daerah rawan longsor yang padat penduduk juga dapat meminimasi terjadinya longsor terutama di tebing yang terletak di tepi jalan.

5. Pemerintah daerah harus mengadakan dan mengawasi proses sosialiasi agar informasi yang disampaikan langsung dapat dimengerti dan dipahami oleh semua warga desa.

\section{DAFTAR PUSTAKA}

Arsyad S. 2000. Konservasi Tanah dan Air. IPB Press

Badan Penanggulangan Bencana Daerah (BPBD). 2013. Jumlah Kecamatan, Desa/Kelurahan dan Penduduk yang Menempati Daerah Rawan Bencana di Kabupaten Tegal Tahun 2013. Laporan Tahunan. 
Balai Besar Litbang Sumberdaya Lahan Pertanian (BBSDLP). 2009. Identifikasi dan Karakterisasi Lahan Rawan Longsor dan Rawan Erosi di Dataran Tinggi untuk Mendukung Keberlanjutan Pengelolaan Sumberdaya Lahan Pertanian. BBSDLP, Bogor.

Bappeda Kabupaten Tegal. 2005. Rencana Pembangunan Jangka Panjang Daerah Kabupaten Tegal Tahun 2005 - 2025.

Undang-Undang Nomor 24 tahun 1992 tentang Penataan Ruang.

Undang-Undang Nomor 24 Tahun 2007 tentang Penanggulangan Bencana.

Undang-Undang Nomor 26 Tahun 2007 tentang Penataan Ruang.

Wuryanta, Agus. 2013. Pemanfaatan Teknologi Sistem Informasi Geografis untuk Pemetaan Lahan Berpotensi Longsor. Prosiding Seminar Nasional Pengelolaan Sumberdaya Alam dan Lingkungan UNDIP, Semarang. 